\title{
Los descriptores de la cartografía temática satelital para la gestión de emergencias pos desastres: caso inundaciones
}

Ponvert Delisles Batista ${ }^{1}$

Elvir Ferman ${ }^{2}$

\section{RESUMEN}

En este trabajo, los autores muestran los resultados de una investigación que cobra gran importancia en la actualidad y que está referida a la caracterización de la cartografía que se elabora con el fin de asistir los procesos de toma de decisiones por los diferentes actores que suelen tomar parte en la evaluación y asistencia en la fase de respuesta pos desastres. La investigación tuvo como motivación central la carencia de bibliografía que muestre los criterios cartográficos que deben cumplir los mapas destinados de este tipo de situaciones, de ahí que el objetivo consistió en "aplicar el marco teórico de la conceptualización de los descriptores cartográficos en la confección de mapas de emergencia pos desastre obtenidos a partir de información satelital". Para cumplimentar dicho objetivo, los autores a partir de la información recopilada por diversas fuentes documentales, han planteado un cuerpo teórico con la conceptualización y adecuación de los descriptores cartográficos para este tipo de mapas y los ejemplifican con dos casos de estudios de mapas que reflejan las consecuencias de un desastre por un evento de inundación. Se concluye que queda evidenciada la importancia de este tipo de mapas para asistir los procesos de toma de decisiones por parte de los gestores de las emergencias pos desastres.

Palabras clave: Cartografía temática, pos desastre, imágenes satelitales, descriptores.

\footnotetext{
${ }^{1}$ Profesor del Instituto Hondureño de Ciencias de la Tierra (IHCIT), Universidad Nacional Autónoma de Honduras, Ciudad Universitaria, Tegucigalpa M.D.C, Honduras, E-mail: damaso.ponvert@unah.edu.hn.

2 Profesor del Instituto Hondureño de Ciencias de la Tierra (IHCIT), Universidad Nacional Autónoma de Honduras, Ciudad Universitaria, Tegucigalpa M.D.C, Honduras. E-mail: oscar.elvir@unah.edu.hn.
} 


\section{ABSTRACT}

In this work, the authors show the results of an investigation that it charges great importance at the present time. It is referred to the characterization of the cartography that is elaborated with the purpose of attending the processes of taking decisions for the different actors that usually participate in the evaluation and attendance in the phase of post disaster response (rescue, relief and recovery). The investigation had as central motivation the bibliography lack that shows the cartographic approaches that should complete the elaborated maps of this type. Therefore, the objective consisted in "to apply the theoretical frame of the conceptualization of the cartographic descriptors in the making of maps of post disaster emergency obtained starting from satellite information". To execute this objective, the authors starting from the information gathered by diverse documental sources, they have outlined a theoretical body with the conceptualization and adaptation of the cartographic descriptors for this type of maps and they exemplify them with two cases of studies of maps that reflect the consequences of a disaster for a flood event. They concludes that the importance of this type of maps is evidenced to attend the processes of taking of decisions on the part of the agents of the post disaster.

Keywords: thematic cartography, post disaster, satellite image, descriptors. 


\section{INTRODUCCIÓN}

Un tema de singular importancia que tiene una influencia decisiva en la elaboración de cartografía temática, tiene que ver con la fuente principal de la cual se extraerán las informaciones de los daños provocados por desastres: las imágenes satelitales. Por ello, se ha dedicado este trabajo a profundizar en los aspectos conceptuales de la cartografía para situaciones de emergencia pos desastre obtenida a partir de información extraída de la huella de los desastres en las imágenes de satélites como fuente principal de datos.

Un primer aspecto abordado es la definición y caracterización del concepto más importante que se trata en el trabajo: la "cartografía de emergencia". Este término, tiene mucho que ver con el ciclo de gestión de los desastres, y por ello, se ha hecho una caracterización que, aunque ya conocida en sus aspectos más generales, ha permitido situar en el lugar adecuado la "cartografía de emergencia" en la fase pos desastre del ciclo, haciendo una descripción detallada de las actividades que hay que ejecutar en las etapas de respuesta de emergencia, rehabilitación y reconstrucción; así como introduciendo los productos cartográficos generales que deberían ser utilizados en cada una.

De esta manera, se llega al concepto de "cartografía de emergencia", el cual se expresa de la manera siguiente: "los procedimientos seguidos en el diseño y producción cartográfica temática para asistir la toma de decisiones en las situaciones creadas por el impacto de eventos causantes de desastres, que están signados por una determinada "urgencia", es decir, por la velocidad o rapidez con que los mismos deban ser confeccionados; y por la inmediatez con que puedan entrar a cumplir sus objetivos en manos de los brigadistas, directivos, personal de las agencias y gobiernos, medios de comunicación etc." y, en consecuencia, se han denominado "mapas de emergencia satelitales" a aquellos mapas temáticos elaborados a partir de la información de la huella de los desastres contenidas en imágenes de satélites, que son confeccionados en plazos de tiempo relativamente breves, y están destinados a reflejar las consecuencias pos desastres y, deben ser entregados a los usuarios potenciales con la inmediatez requerida para que puedan hacer uso de los mismos con efectividad.

Otro aspecto importante es que se define la tipología de mapas que se consideran dentro de esta categoría: "mapas de respuesta" y "mapas de rehabilitación o de recuperación de daños", haciendo alusión a las etapas del ciclo de manejo del desastre 
para los que son realizados. Se ofrece una caracterización de la información temática y los elementos cartográficos que deben contener, y se ejemplifica con casos de estudios realizados por distintas agencias de atención a emergencias. Las caracterizaciones que se han hecho hasta el momento de este tipo de mapas, han sido muy generales, por lo que se considera, los mismos deben reunir una serie de propiedades inherentes a todo producto cartográfico, dadas por sus descriptores geométricos, semánticos y topológicos, aspectos que se tratarán a continuación de manera general y luego ejemplificándolos en cada uno de los tipos de mapas de emergencia definidos.

A partir de la necesidad de utilizar criterios cartográficos bien definidos y fundamentados, que contribuyan a fortalecer la pertinencia de los mapas destinados a apoyar las tareas de evaluación y seguimiento durante la etapa de respuesta en el ciclo de gestión de los desastres, el presente trabajo se realizó con el objetivo siguiente: "aplicar el marco teórico de la conceptualización de los descriptores cartográficos en la confección de los mapas de emergencia obtenidos a partir de información satelital".

\section{MATERIALES}

Como materiales fundamentales para el análisis se utilizaron los siguientes:

- Mapas digitales sobre la evaluación y caracterización del impacto de eventos desastrosos realizados por mecanismos y agencias de producción cartográfica internacionales.

- Bibliografía relevante sobre el tema para profundizar en la conceptualización del marco teórico soporte de la investigación

\section{METODOLOGÍA DE INVESTIGACIÓN}

Para realizar la investigación, se utilizó el método cualitativo basado en la investigación documental. Se adoptó este método por ser uno de los más apropiados para cumplir con el objetivo que el objetivo propuesto. Para llevarlo a cabo se acudió al auxilio de la técnica de observación documental de fuentes cartográficas obtenidas mediante buscadores de internet y el estudio de numerosos documentos bibliográficos sobre el tema (gmes, 2018a y 2018b, la carta, 2011, copernicus.eu). 
El análisis realizado de la información obtenida, permitió elaborar un cuerpo teórico con la conceptualización del objeto de estudio: Los descriptores cartográficos de los mapas, a partir de los cuales, se realizaría una adecuación para el caso de la cartografía temática satelital.

El cuerpo teórico abarca la descripción de los descriptores cartográficos que todo mapa debe reunir, estructurados en tres dimensiones: geométricos, semánticos y topológicos cuyos contenidos se muestran a continuación, aplicados a los mapas elaborados con el fin de apoyar la gestión de riesgos y desastres, denominados genéricamente como "mapas de emergencia" y en el caso específico de los obtenidos a partir de información satelital "mapas de emergencia satelitales".

\section{Los descriptores geométricos de los "mapas de emergencia"}

Los mapas temáticos en general, deben cumplir una serie de exigencias desde el punto de vista cartográfico, que son definidas por distintos tipos de descriptores. Según Durand (1993), los descriptores geométricos son aquellos que, en un mapa permiten encontrar respuesta a la pregunta ¿dónde está situado el objeto analizado? Los mapas de emergencia pos desastres no son la excepción, pues, igualmente son productos cartográficos temáticos que representan la huella del impacto de un desastre y deben responder a esta pregunta, determinando las coordenadas $x, y, z$ de los objetos, rasgos y señales que la integran, que no es más que la definición de la posición de cada uno en el plano.

La posición de los objetos, es la cualidad que define la ubicación exacta de ellos en el mapa, mediante un sistema de coordenadas geográficas o planas. Esta cualidad es, en última instancia, la que determina la precisión de un mapa, condición que se alcanza cuando la posición de los objetos y lugares que en él figuran son rigurosamente homólogas con las que estos mismos objetos y lugares ocupan sobre el terreno, en relación dada por la escala. En otras palabras, en dependencia de la colocación y el trazado de los diversos elementos gráficos, dependerá la precisión de un mapa (Joly, 1979).

Pero además de su posición, los descriptores geométricos en un mapa definen los criterios de forma, tamaño o dimensión, y orientación, que deben observarse en el diseño y elaboración de los mismos para facilitar en última instancia, la comprensión correcta de la idea que se quiere trasmitir a los usuarios potenciales del documento. En cuanto a la forma, un mapa está completamente repleto de formas diferentes, dadas por las características de los objetos o imágenes que contiene. Estos objetos 
son representados por símbolos figurativos, que ocupan sobre la hoja cartográfica una superficie más o menos extensa, según se trate de un punto (implantación puntual), una línea (implantación lineal); o una zona o región (implantación zonal) (Joly, 1979).

Al considerar el tamaño de los objetos, los mapas temáticos están llenos de objetos diferentes no solo en lo referente a su forma sino también en cuanto a su tamaño. Así, por ejemplo, para Joly (1979) un símbolo en implantación zonal tiene necesariamente la forma y el tamaño de la superficie que recubre; cualquier variación de su forma 0 tamaño significa necesariamente una variación de la forma o tamaño de la superficie representada. Sin embargo, es posible variar el tamaño de los símbolos elementales que constituyen el símbolo principal instalado sobre la zona, del mismo modo, los signos puntuales o lineales pueden variar de tamaño sin dejar de caracterizar el punto de aplicación o el eje de la figura sobre los que están aplicados. La variación del tamaño es una variable fuerte, muy perceptible, que permite una buena selección de los caracteres de los objetos; pero, naturalmente, adquiere toda su eficacia cuando esta selección se hace sobre dimensiones diferenciales.

En cuanto a la orientación o disposición de los objetos, Joly (1979) señala que, es posible dar a un signo puntual orientaciones diferentes, aunque en número limitado, si han de distinguirse claramente. Un trazo puede ser vertical, horizontal o inclinado hacia la derecha o hacia la izquierda; un triángulo puede tener su base arriba, abajo a la derecha 0 a la izquierda; un semicírculo puede ser cóncavo o convexo con relación a una dirección dada. La única figura no orientable es el círculo, aunque puede llegar a serlo, si se dibuja uno de sus diámetros. De igual modo una zona, o una línea suficientemente gruesa pueden ser sombreadas en diferentes sentidos, mediante líneas verticales, horizontales u oblicuas.

En resumen, los descriptores geométricos cobran una importancia crucial en cualquier tipo de mapa, pues de la manera en que sean utilizados para representar un fenómeno en específico que, en este trabajo, está relacionado con la huella medioambiental o daño provocado por los desastres, será la eficacia que se consiga en el mensaje que se quiera transmitir a los usuarios potenciales de los mismos.

\section{Los descriptores semánticos de los "Mapas de emergencia"}

La semántica es la disciplina que se ocupa del significado de los signos lingüísticos: palabras, oraciones y textos (no estudia las unidades del nivel fónico, los fonemas y los sonidos, puesto que no tienen significado). (Léxico y semántica, en: 
http://www.mcgraw-hill.es/bcv/guide/capitulo/8448150007.pdf).

Al hacer una trasposición del término a la cartografía, la semántica se encargaría de estudiar el significado de los signos y gráficos y las relaciones existentes entre las diferentes unidades lingüísticas utilizadas en los mapas, mediante la toponimia. En definitiva en los mapas temáticos de cualquier tipo, se usan un conjunto de símbolos que transmiten ideas y mensajes. Esto es la simbología gráfica, es el lenguaje de la representación cartográfica y es una parte de la semántica cartográfica, pero en un mapa no solo se utilizan símbolos (signos, gráficos e imágenes), sino también las descripciones textuales para denotar estos elementos gráficos y sus relaciones, es decir, el campo de la toponimia. Según el mismo diccionario antes citado, la toponimia se dedica al estudio de "los lugares de una región o idioma", al "estudio de los nombres de esos lugares", al "estudio de los topónimos".

En un mapa temático, los descriptores que respondan a la pregunta: ¿De qué naturaleza es este objeto?, se les llaman semánticos, y normalmente para responder a tal pregunta se debe acudir a la leyenda del mapa. Cuando se trata de generar mapas a partir de información satelital, es una condición indispensable que dichas imágenes sean previamente tratadas para extraer la información temática de interés.

Según Joly (1979), la expresión cartográfica resulta de la producción masiva o simultánea de imágenes significativas (no precisamente imágenes de teledetección). El lector percibe cada una de ellas en un instante, y las agrupa cerebralmente de manera conjunta y coordinada, lo que permite comprender el mensaje enunciado. En la medida en que la cartografía pueda ser considerada como un lenguaje, podría compararse cada imagen con las palabras de la frase hablada, formadas ellas mismas por letras, que equivaldrían en nuestro caso a signos y símbolos. Dichas imágenes se combinan en la mente del lector, como las palabras en la frase, formando una serie lógica e inteligible, que es como la gramática del lenguaje cartográfico, y con un cierto estilo, que estriba en la calidad y elegancia de la presentación. De esto se encarga la semiología, es decir, de estudiar y conocer las propiedades de ese lenguaje cartográfico para utilizarlo mejor.

La semántica (de semiología) está muy relacionada con la comunicación, es decir con lo que se quiere trasmitir al usuario. Como es conocido, todo proceso de comunicación es la transferencia de información de una persona o grupo de personas a otra persona u otro grupo de personas distinto. Para que una comunicación sea efectiva se requiere: i) emisor de la información; ii) mensaje; iii) medio por el que comunicarse; y iv) receptor. 
Haciendo una transposición de ideas al campo de la cartografía temática de emergencia, el emisor de información sería el cartógrafo; el mensaje, es el conjunto de la información que se desea trasmitir, en este caso, la información temática sobre la huella medioambiental producida por los desastres extraída de las fuentes de información; el medio, es el conjunto de símbolos, gráficos e imágenes que conforman el mapa; y lógicamente el receptor, es el usuario del mapa, siendo los más comunes las agencias de protección civil de los países, las que evalúan la ayuda a aportar para las situaciones de crisis, y otras de los mecanismos internacionales interesados en evaluar la magnitud del daño con diferentes fines. Es condición indispensable que el receptor y el emisor entiendan los símbolos con que se emite la información y en esto la semántica cartográfica juega su papel fundamental.

En el caso de los mapas temáticos -como el resto de los mapas-, contienen información, lo único que esta información se refiere a un tema específico, además esta información se presenta en forma gráfica, es decir mediante la utilización de un conjunto de símbolos, diagramas, o una imagen pseudo-pictórica (que en el caso de los mapas obtenidos a partir de datos satelitales, la imagen satelital es la portadora de la información fundamental); y esta información será representada de manera tal que el usuario del mapa sea capaz de entenderla, de interpretarla (Bernabé e Iturrioz, 2009).

Así que, la semántica cartográfica estará en el centro de los procesos de diseño, elaboración e interpretación de los mapas temáticos, y una muestra de ello es el análisis que se hace de los criterios a tener en cuenta para la representación de los elementos característicos de la huella de los distintos tipos de desastres con vistas a su mejor representación en los "mapas de emergencia".

\section{Los descriptores topológicos de los "Mapas de emergencia"}

Para que mediante un mapa se pueda responder a la pregunta: ¿Cuáles son las relaciones entre los objetos analizados?, hay que recurrir a los descriptores topológicos. Y en el caso de los mapas temáticos en general y, de los "mapas de emergencia" en particular, la respuesta a esta interrogante estaría dada por la posibilidad de interpretar los objetos representados en relación con los objetos del entorno con vista a extraer de ellos la información temática de interés.

Otro autor, Felicísimo (2010), en su glosario de términos usados con SIG, la topología hace referencia a las propiedades no métricas de un mapa. En el contexto de los SIG, topología hace referencia a las propiedades de vecindad o adyacencia, inclusión, 
conectividad y orden, es decir, propiedades no mesurables y que permanecen invariables ante cambios morfológicos, de escala o de proyección. Se dice que una estructura de datos es 'topológica' cuando incluye información explícita sobre estas propiedades; en este caso, es posible realizar análisis y consultas "topológicas" sin necesidad de acudir a las tablas de coordenadas.

En el caso de los mapas de emergencia la propiedad de vecindad, se refiere a la proximidad de los elementos dentro de una clase dada o con respecto a otra clase y se manifiesta por la distancia existente entre un punto tomado en la clase de referencia y otro punto (pixeles si la imagen es digital). La adyacencia se refiere a los puntos de contacto limítrofes entre dos clases contiguas de un mapa temático, lo cual está relacionado con su vecindad. La inclusión está referida a la pertenencia de un elemento (punto o pixel) a un conjunto dado de puntos de una o varias clases temáticas. La conectividad refiere la manera en que dos o más puntos de una o de varias clases están conectados; y el orden se refiere a la posición que ocupan los puntos uno con respecto a otros considerando un origen dado.

Todas estas propiedades enunciadas, están presentes en los mapas temáticos, aunque los usuarios no las perciban de manera consciente, pero que en su conjunto tienen una repercusión incuestionable en la semántica cartográfica.

A modo de conclusiones para el caso de los mapas de emergencia, se muestra la tabla 1, en la cual se comparan para mejor comprensión los distintos descriptores para diferentes tipos de productos de información geoespacial. El análisis de la misma, destaca que los mapas de emergencia se presentan en una forma idéntica que los mapas tradicionales (topográficos), en términos de geometría y de manera similar con respecto a los descriptores gráficos (informaciones periféricas del mapa, base matemática-cartográfica), pero, la diferencia esencial reside en que la información semántica en los "mapas de emergencia", estaría representada en distintos grados, dependiendo lógicamente de su naturaleza y carácter temporal; mientras que, en un mapa tradicional, está sistemáticamente explicitada.

En el acápite de resultados, se muestra la aplicación este marco teórico metodológico a casos reales de confección de distintos tipos de "mapas de emergencia" pos desastres por eventos de inundación realizados por diferentes agencias de producción cartográfica al servicio del mecanismo de la carta internacional del espacio y grandes catástrofes. 
Gráfico 1. Eficiencia termodinámica de las plantas de potencia propuestas

\begin{tabular}{|c|c|c|c|}
\hline \multirow{2}{*}{$\begin{array}{c}\text { Productos } \\
\text { geoespaciales }\end{array}$} & \multicolumn{3}{|c|}{ Descriptores } \\
\hline & Geométricos & Semánticos & Topológicos \\
\hline $\begin{array}{l}\text { Imagen de satélite } \\
\text { (bruta) }\end{array}$ & No existen & No existen & Implicitos \\
\hline $\begin{array}{ll}\text { Mapas } & \text { de } \\
\text { Emergencia } & \\
\end{array}$ & $\begin{array}{l}\text { Referenciales } \\
\text { cartográficos }\end{array}$ & $\begin{array}{l}\text { De inexistentes a explícitos } \\
\text { (mediante una leyenda) }\end{array}$ & Implícitos \\
\hline Mapa topográfico & $\begin{array}{l}\text { Referenciales } \\
\text { cartográficos }\end{array}$ & Explicito (leyenda) & $\begin{array}{llr}\text { Implícitos } \quad \text { (con } & \text { una } \\
\text { descripción } & \text { "compacta } & \text { y } \\
\text { cerrada" de los objetos. } & \end{array}$ \\
\hline SIG & $\begin{array}{l}\text { Referenciales } \\
\text { cartográficos }\end{array}$ & Explicito (leyenda) & Explícitos \\
\hline
\end{tabular}

Fuente: Adaptado de Galtier 1992b

\section{RESULTADOS}

Caso 1. Los descriptores cartográficos en los mapas de respuesta de emergencia por inundación descriptivos.

En los días finales del mes de octubre de 2008 lluvias intensas causaron inundaciones en diversos estados de México afectando las áreas agrícolas, autopistas y carreteras y miles de viviendas. Los poblados de Temosique, Balancín, Emiliano Zapata y Jonula, localizados a lo largo del río Usumacinta fueron particularmente afectados. De manera similar a las inundaciones ocurridas en el año 2007, las áreas alrededor de Villahermosa fueron también impactadas por las aguas acumuladas.

El mapa de la figura 1 muestra la extensión de la inundación en la región de Villahermosa, México, registradas en una imagen de radar proveniente del satélite alemán terrasar-x adquirida en noviembre 1 de 2008. Este satélite es operado de manera conjunta por el centro aeroespacial alemán (DLR) e infoterra gmbh.

El procesamiento de las imágenes consistió en la utilización de una imagen de archivo del satélite landsat-7 etm+ (30 metros de resolución espacial) por razones de visualización, es decir, por permitir una visualización completa del área, sin cobertura de nubes, la cual se utilizó como telón de fondo (referencia) sobre la cual se fusionó con la imagen del terrasar- $\mathrm{x}$.

El mapa de respuesta de emergencia fue elaborado para apoyar a la agencia de 
protección civil de México (CENAPRED) y a la Comisión Nacional del Agua (CONAGUA) en los análisis de la situación creada de manera súbita. Este procesamiento permitió apreciar por una parte, el nivel normal del agua (color azul celeste en la imagen landsat-7 etm) y la extensión alcanzada por el evento de inundación (color azul intenso en la imagen del terrasar-x), así como las instalaciones y áreas agrícolas bajo riesgo por la inundación. Se utiliza una leyenda que permite apreciar sin mayores esfuerzos esta información semántica.

Figura 1. Mapa de respuesta a la emergencia de inundación (descriptivo) a escala $1: 125.000$

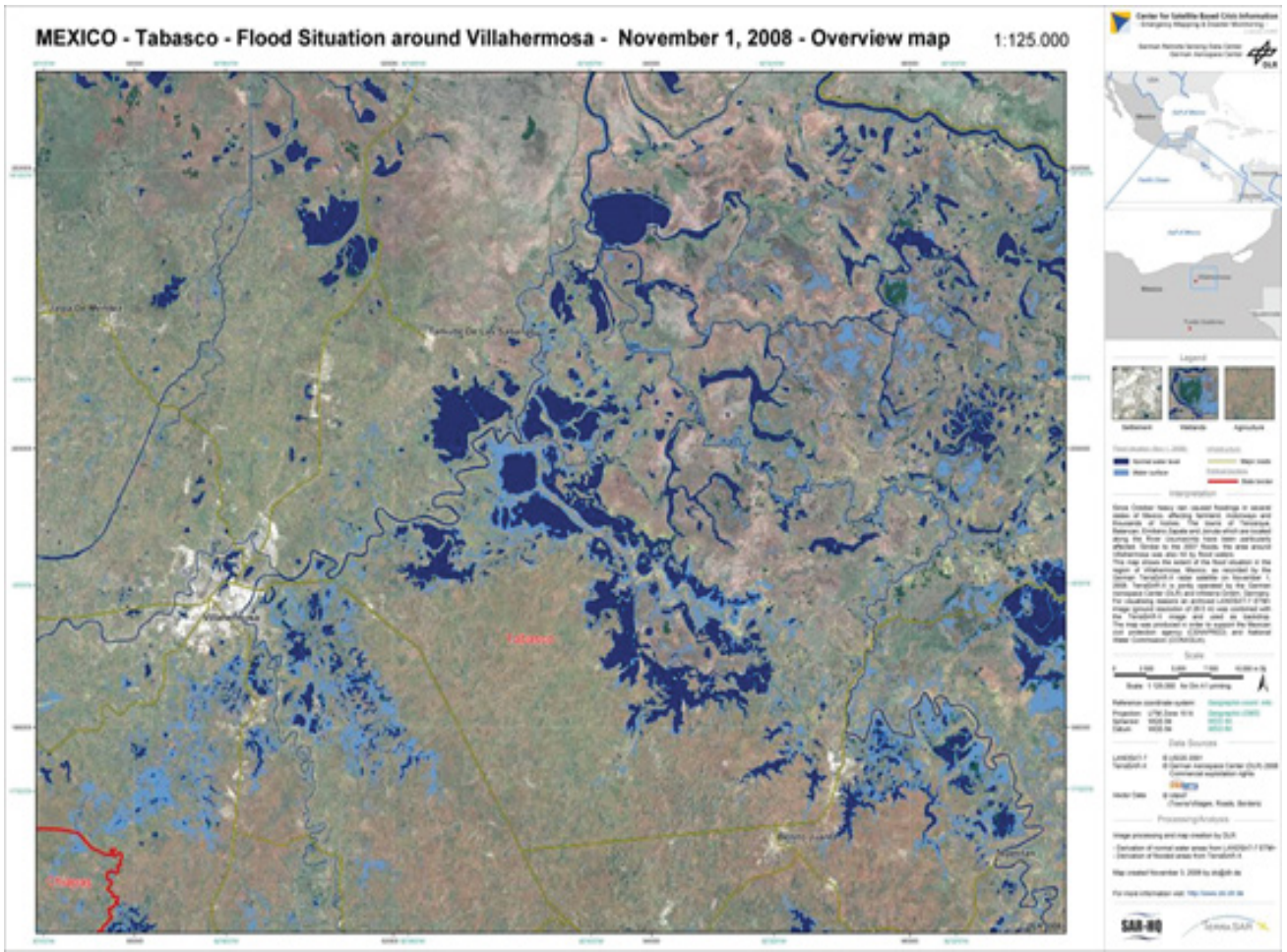

Fuente: Disponible en http://www.zki.dlr.de/map/271

Los descriptores geométricos se aprecian en los datos siguientes:

- La escala de representación: 1: 125.000

- Sistema de coordenada de referencia:

> Proyección: utm zona $15 n$

> Esferoide: wgs 84

> Datum: wgs 84 
- Sistema geográfico de información:

> Proyección: geographic (dms)

, Esferoide: wgs 84

, Datum: wgs 84

Los descriptores topológicos están implícitos en los datos fuentes utilizados para confeccionar el producto:

- Imagen landsat-7 etm+ de referencia perteneciente al USGS 2001

- Imagen terrasar-x del centro aeroespacial alemán (DLR) 2008

- Derechos comerciales pertenecientes a infoterra.

Los descriptores semánticos se manifiestan en:

- La leyenda utilizada para representar los aspectos temáticos de la extensión del daño que, en este caso, permite distinguir las áreas abarcadas por el evento de inundación, de las aguas originales, así como otros elementos ambientales (clases) del contexto: agricultura, urbanizaciones.

- Otros elementos gráficos contenidos en el margen del mapa, que contribuyen a su interpretación, como son la macro y micro localización.

- Datos vectoriales: ciudades, poblados, carreteras y límites administrativos.

Caso 2. Los descriptores cartográficos en los mapas de respuesta de emergencia detallados.

Una semana de intensas lluvias provocó el desborde de ríos, sumergiendo la mayor parte del estado de tabasco y de zonas aledañas del estado de Chiapas. La ciudad de Villahermosa con una población de más de un millón de habitantes fue la más afectada por el evento de inundación. El mapa de la figura 2 muestra la situación detallada del grado de la inundación en la ciudad (región) de Villahermosa, tabasco, México, según se aprecia en una imagen de radar adquirida por el satélite alemán terrasar-x el 10 de noviembre de 2007. 
Figura 2. Mapa de respuesta de emergencia detallado a escala 1:15.000.

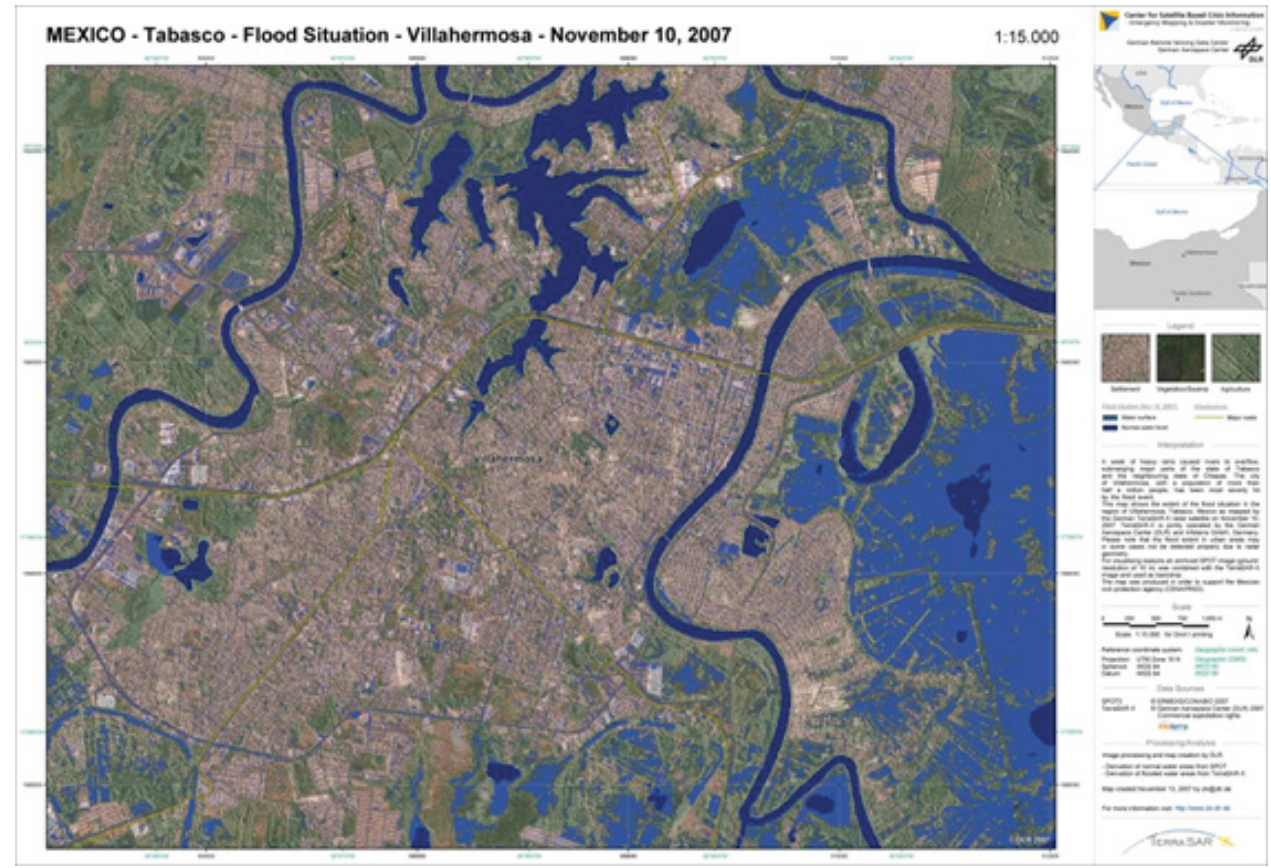

Fuente: Disponible en http://www.zki.dlr.de/map/408

Nótese la diferencia en los contenidos de información semántica sobre el daño provocado por el evento entre este mapa y el anterior. En este caso, se ha abierto una ventana a una escala de más nivel de detalle $(1: 15.000)$ que permite apreciar el alcance de la inundación en el interior del área urbana, gracias a las capacidades de las imágenes de radar de facilitar la identificación de zonas de abundante humedad, de presencia de agua y los límites de frontera tierra-agua, aunque se señaló por los productores que debido a la geometría del radar, no fue posible detectar la presencia de agua en algunas áreas del tejido urbano. También el nivel de detalle permitió considerar otras clases en la leyenda no presentes en el mapa anterior.

En este caso el procesamiento se realizó utilizando una imagen spot multiespectral adquirida antes de la ocurrencia del evento (fase predesastre) con una resolución espacial de 10 metros, como imagen de fondo, la cual fue combinada de manera similar al caso anterior, superponiéndole la imagen radar del terrasar-x.

En cuanto a los descriptores geométricos y topológicos, no aparecen diferencias sustanciales con respecto al mapa anterior y se manifiestan por los mismas elemen- 
tos: Los sistemas de referencia geodésicos y las escalas para el primero; mientras que los rasgos que definen al segundo, permanecen implícitos y no son posibles de apreciarse visualmente.

\section{CONCLUSIONES}

El tema tratado no es común en la literatura sobre cartográfica temática en general y satelital en particular, para asistir las emergencias pos desastres, de ahí su novedad.

Queda evidenciada la importancia de este tipo de mapas para asistir los procesos de toma de decisiones por parte de los gestores de las emergencias pos desastres, en particular los organismos de protección civil encargados de la respuesta, así como para los mecanismos y agencias internacionales que prestan apoyo en los lugares del desastre para la canalización de la ayuda nacional o internacional.

Se recomienda la aplicación del enfoque de los descriptores en la confección de otros tipos de mapas de emergencia, no solo para los de evaluación preliminar del impacto del evento desastroso en la respuesta inmediata, sino también para los mapas destinados a apoyar las tareas de rehabilitación y reconstrucción.

\section{REFERENCIAS BIBLIOGRAFÍCAS}

Bernabé e Iturrioz, (2018). Elementos del diseño cartográfico. Cap. 1 introducción al diseño cartográfico. En elementos del diseño cartográfico, 7 p. Disponible en: http://redgeomatica.rediris.es/carto2/pdf/pdfb/tema9b.pdf.

Cauvin, C., F. Escobar and A. Serradj, (2010). Thematic cartographic and transformations, GIS, geographical information systems series, volume 1, Wiley \& Son, Inc., Iste Itd., 464 p.

Cauvin, C., F. Escobar and A. Serradj, (2010). New approaches in thematic cartography, GIS, geographical information systems series, volume 3, Wiley \& Son, Inc., Iste Itd., 476 p.

Claret, R., C. Cabrera y I. Ramírez (2010). Cartografía temática. Representaciones cartográficas de implantación puntual y lineal: elaboración mediante sistemas de información geográfica, Revista Geográfica Digital. Igunne. Facultad de humanidades. UNNE. Año 7. no 14. Julio - diciembre 2010. Resistencia, Chaco.

Coll, E., J. Martínez, J. Sanz and J. Irigoyen (2005). Introducción a la publicación de cartografía en internet, Valencia, dpto. de ingeniería cartográfica, geodesia y fotogrametría, 
Universidad Politécnica de Valencia, 167 p.

Copernicus.eu_a, Copernicus emergency management service, European Commission. Disponible en: http://emergency.copernicus.eu/.

Copernicus.eu_b, Copernicus emergency management service-mapping, European Commission. disponible en: http://emergency.copernicus.eu/mapping/.

Durand, D., (1993). Cuaderno a1. Las espacio cartas. Métodos y ejemplos de realización. Los cuadernos pedagógicos del GDTA, versión no. 1.0, GDTA. Ediciones Universidad Católica de Chile.

Felicísimo, A.M, (2009). Medida, control y propagación del error, tema 3 del curso de MDT, Universidad de Extremadura, España. Disponible en: http://www6.uniovi.es/ feli/cursomdt/tema_3.pdf.

Gmes, 2018a, emergency response service Gmes, rapid mapping product portfolio, emergency management service. Disponible en: http://emergency.copernicus.eu/mapping/sites/default/files/files/copernicusems-service_portfolio-rapid_mapping.pdf. .

Gmes, 2018b, emergency response service Gmes, risk and recovery mapping product portfolio. Disponible en: http://emergency.copernicus.eu/mapping/sites/default/files/files/coper nicusems-service_portfolio-risk_and_recovery_mapping.pdf.

Ica, (asociación internacional de cartografía). (1993). Cartografía ii: ficheros. Cartografía temática: capítulo 1: introducción a la cartografía temática. Disponible en: http://redgeomatica.rediris.es/carto2/pdf/pdfcurso.html.

Joly, f., (1979). La cartografía. Colección el cano. La geografía y sus problemas, 303 p. Barcelona: Editorial Ariel

La carta internacional del espacio y grandes catástrofes (2011). Activaciones. Disponible en: https://disasterscharter.org/web/guest/activations/charter-activations/

Léxico y semántica. Disponible en: http://www.mcgraw-hill.es/bcv/guide/capitulo/84481500 07.pdf. 